\title{
Editorial \#14 Ambiente y extensión universitaria
}

\author{
Cecilia lucci \\ Universidad Nacional del Litoral, Argentina. \\ ciucci@unl.edu.ar \\ (DD orcid.org/0000-0003-0073-2124
}

La preocupación por la cuestión ambiental adquiere cada vez más relevancia en la agenda pública internacional, al menos desde hace seis décadas. Sin embargo, organismos internacionales, distintos niveles de gobierno, organizaciones no gubernamentales y medios de comunicación toman en consideración este tema de manera dispar, fragmentada y contradictoria. Su abordaje supone tensionar visiones sobre la naturaleza y la sociedad desde la política, la economía, la ciencia y la religión, en las que se involucran sujetos, territorios, "recursos" y significados diferentes que inciden sobre el devenir humano y planetario. Formas de producir, de estar, de convivir y sentir el mundo, atravesadas por fuertes disputas políticas, corporativas y culturales.

La gestión ambiental, los esfuerzos en pos de mitigar algunas problemáticas ambientales, las disputas y los cuestionamientos sobre las formas de producir, consumir y desechar, la preservación y la búsqueda de relaciones más armónicas entre sociedad y naturaleza, son algunos de los puntos que ponen de relieve distintas racionalidades, intereses y conflictos en torno al ambiente.

La pandemia no ha hecho más que visibilizar estos escenarios en un presente marcado por la incertidumbre pero que no llega a confrontar lo suficiente con un futuro con pocas probabilidades de subsistencia. El hoy disputa ahora los sentidos de la nueva normalidad.

La Universidad ha incluido estas preocupaciones en la enseñanza a partir de nuevas carreras de grado y posgrado así como con la incorporación de contenidos en las ya existentes y en sus líneas de investigación y de extensión. Justamente, se observa un rol muy importante de los equipos extensionistas en la articulación con sujetos e instituciones para el planteo y la búsqueda de construcción de propuestas de mejora ante distintas problemáticas ambientales. Mejor aun, cuando se construyen espacios de integración de las funciones universitarias, en donde las agendas de investigación se alinean sobre problemas ambientales relevantes. Agendas en las que los sujetos sociales tienen participación activa respecto de su definición y en la búsqueda de soluciones a partir de intervenciones específicas. Agendas en donde la currícula también es interpelada desde estas trayectorias.

En particular, desde la extensión universitaria se viene trabajando la cuestión ambiental (en sentido amplio). Entonces, nos preguntamos: ¿cómo se reflexiona teóricamente sobre el ambiente desde las intervenciones vinculadas al campo de la extensión? ¿Qué metodologías se utilizan? ¿Cómo los equipos extensionistas establecen relaciones con los sujetos, los movimientos sociales y el Estado frente alguna problemática de carácter ambiental? ¿Qué propuestas de mejora se construyen desde las intervenciones extensionistas de manera colaborativa con esos actores? ¿Qué rol ocupan los Objetivos de Desarrollo Sostenible (ODS) que retoman la preocupación por el ambiente en los proyectos de extensión universitaria?

De este modo, la convocatoria 2021 de $+\mathrm{E}$ hizo foco en los procesos de extensión universitaria vinculados a la cuestión ambiental. Para llevar adelante esta convocatoria, nos acompañaron Enrique Mihura, Alba Imhof y Patricia Mines, del Programa de Extensión Am- 
biente y Sociedad de la Secretaría de Extensión Social y Cultural (SESyC) de la Universidad Nacional del Litoral (UNL). Con ellos también planificamos un ciclo de conversatorios ligados a esta convocatoria. Se trató de cuatro encuentros virtuales en los que nos acompañaron el Foro Latinoamericano de Ciencias Ambientales (FLACAM), la Asociación Argentino Uruguaya de Economía Ecológica (ASAUEE), la Asociación de Escuelas y Facultades de Arquitectura Públicas de América del Sur (Arquisur), y la Red de Universidades Argentinas para la Gestión Ambiental y la Inclusión Social (RED UGAIS). Los conversatorios se encuentran disponibles en la lista de reproducción del canal de YouTube de la SESyC de la UNL.

En este número de $\mathbf{+ E}$, dos artículos componen la sección Perspectivas. Las autoras de la Universidad de Buenos Aires (UBA), Argentina, reflexionan sobre los aportes de la Universidad Campesina en Santiago del Estero al movimiento indígena-campesino y a la construcción de la soberanía alimentaria. El segundo artículo aborda, desde la trayectoria de la autora en la Universidad Nacional de Luján (UNLu), Argentina, las prácticas integrales vinculadas a conflictos ambientales producidos por las inundaciones y por empresas megamineras.

En la sección Desafíos de Gestión, el Programa de Ambiente y Extensión de la UNL da cuenta de su trayectoria y de los debates en estos 15 años de trabajo. Desde el Espacio de Formación Integral "Relaciones sociedad-naturaleza en la frontera", de la Universidad de la República (UdelaR), Uruguay, se recogen las reflexiones de un equipo que realiza extensión universitaria desde una perspectiva integral en un área protegida del noreste de Uruguay. Por último, desde la Facultad de Periodismo y Comunicación Social de la Universidad Nacional de La Plata (UNLP), Argentina, se presentan dos conceptos emergentes de la praxis en procesos de extensión e investigación-acción, Agendas Científicas Participativas y Mesas de Trabajo Permanentes, que toman como punto de partida una trágica inundación en La Plata.

En la sección Intervenciones, cinco artículos toman las líneas de la convocatoria. Autores de la Facultad de Ciencias Agrarias y Forestales de la UNLP abordan la experiencia de construcción de los Faros Agroecológicos que sintetizan el objetivo de difundir, desarrollar y evaluar estrategias y tecnologías de base agroecológica apropiadas para y con productores familiares de la región Pampeana. La autora perteneciente a la Universidad Nacional del Noroeste (UNNE) de la provincia de Buenos Aires, Argentina, analiza un proyecto de extensión y de investigación ligado a la implementación de prácticas de sostenibilidad ambiental y energética en una escuela secundaria de formación agraria. Desde la Universidad Nacional del Sur (UNS), Argentina, los autores dan cuenta del recorrido del proyecto "Inundaciones: ¿qué podemos hacer? Las tecnologías colaborativas en la gestión del riesgo", en el cual la participación ciudadana fue un pilar fundamental para reconstruir el conocimiento en torno al riesgo de inundación y reflexionar en virtud del accionar de cada uno de los actores desde la extensión universitaria. El cuarto artículo refiere a una experiencia realizada por la UdelaR para implementar procesos participativos en la realización de un monitoreo de la calidad de agua del río Tacuarembó. El quinto artículo refiere al trabajo llevado a cabo por el Grupo Aguas de la Universidad Nacional de Mar del Plata (UNMdP), Argentina, en un barrio de la provincia de Buenos Aires donde se desarrolló un proceso de organización en torno a la problemática del consumo de agua no potable.

En la sección Reseñas, se refieren tres libros: La comunicación en los territorios. Experiencias en la construcción colectiva del conocimiento, con textos compilados por Néstor González y Alfredo Alonso; Extensão Universitária: trajetórias e desafíos, escrito por Sandra 
De Deus; y Los caminos de la Extensión en Colombia, cuyas compiladoras son Sylvia María Valenzuela Tovar y Ruth Marcela del Campo Machado. A su vez, en esta sección se inaugura la posibilidad de reseñar tesis. En esta oportunidad se reseña la tesis doctoral de Alfredo Balduino, A curricularização da extensão universitária a partir do plano nacional de Educação do Brasil: dificuldades e possibilidades.

En la sección Apuestas, dos áreas de gestión de la SESyC de la UNL refieren a la reconfiguración de los dispositivos institucionales para trabajar durante la pandemia.

Finalmente, como siempre lo hacemos, agradecemos a todos los autores que postularon sus artículos en esta convocatoria de $+\mathbf{E}$ por la confianza expresa hacia nuestra revista y a los revisores que año tras año se comprometen para velar por la calidad de las producciones. 